\title{
Understanding and Achieving Quality in Sure Start Children's Centres: Practitioners' Perspectives
}

\begin{abstract}
This article focuses on some of the issues that shape understandings of professional practice in the rapidly expanding children's centre context in England. Drawing on data from an ESRC-funded project exploring practitioners' understandings of quality and success, the perspectives of 115 practitioners working in eleven Sure Start Children's Centres are presented. The findings indicate that the practitioners' definitions of quality and success are influenced by contextual elements, such as the organisational climate in which they work, as well as the wider political agenda and their individual histories. Putting practitioners' understandings of quality into practice presents challenges on various levels as they search for new ways of working in order to provide 'joined up' provision that will work for children and their families as required by current policy.
\end{abstract}

Keywords: quality; success; early years; children's centre; Sure Start

\section{Introduction}

Between 1997 and 2010, the incumbent government in the UK (the Labour

Government) introduced a number of policies in relation to Early Years practice and made significant changes to children's services in England. This article draws upon data from a studylocated within this period; the Understanding Quality project ${ }^{\mathrm{i}}$.

'Quality' and 'success' were central themes within the Labour Government programme and the study sought to explore early years practitioners' perspectives on these concepts in within a rapidly changing landscape of early years services.

'Practitioner' is an inclusive term used to encompass a range of roles within children's services. In this study this term is used to denote nursery nurses, teachers, teaching assistants and head teachers working in nurseries, schools and Sure Start Children's Centres. Sure Start (DfEE 1998) was one of the Labour Government's flagship policies. Realised as local intervention programmes, Sure Start Local Programmes (SSLPs) were designed to improve outcomes for children and families. These were flexible, community-based initiatives that promoted an integrated coordinated approach that enabled users to access a variety of services through a 
single hub. SSLPs developed in conjunction with other programmes such as Neighbourhood Nurseries and Early Excellence Centres which piloted integrated centres. The Sure Start Children's Centre model was adopted on a national scale based on these initiatives (HM Treasury 2004) following the Every Child Matters green paper (DfES 2003a) which set out plans for multi-disciplinary approaches to children's services (Anning et al. 2010; Baldock et al. 2009). The development of Sure Start Children's Centres has been rapid; from 188 in January 2005 to over 3,500 by 2010 (DCSF 2010). However, the Labour Government lost the election of 2010 and a new Coalition government was formed, heralding changes to the services offered by Sure Start Children's Centres (Daycare Trust 2010). This article explores the visions of 'quality' articulated by some of the practitioners working in Sure Start Children's Centres and the issues around achieving these.

\section{Background of the study}

The following offers a brief account of recent government reforms and introduces research pertinent to the discussion of 'quality' in the context of Sure Start Children's Centres.

\section{'Quality' and the Early Years: reform and debate in recent years}

The former Labour government considered early years policy to be a key driver in achieving the wider socio-political goals of eradicating poverty and promoting social inclusion (Baldock et al. 2009). Policy-makers were committed to improving quality in all early years settings through a consistent standards-based approach that brought together education and care (DCSF 2007a). This included measures such as the introduction of the Early Years Foundation Stage (EYFS) (DCSF 2007b), hailed as 'a single quality framework for services to children from birth to five' (DCSF 2006). The independent watchdog, Ofsted (the Office for Standards in Education, Children's 
Services and Skills), was charged with developing an inspection service for all early years provision, expanding on their previous duty to government-funded settings only. In addition, the Children's Workforce Strategy (DfES 2006) was introduced to increase the recruitment and retention of quality staff by clarifying progression routes and raising qualification levels. For staff in local council-funded settings, this was combined with the Single Status Agreement (NJC 1997, p. 4.1.2) which was intended to 'incorporate the principle of equal pay for work of equal value'. As a result of reforms such as these, expenditure on early years services quadrupled to $£ 4.4$ billion between 1997 and 2008, making the UK one of the highest spenders in Europe (Pugh 2010). But there has been a confusing array of 'reorganisations, restructurings and "rebrandings" (Penn 2008, p. 127) creating tensions between the policies that promote flexibility and choice and those that establish centrally prescribed targets. The introduction of a complex system of monitoring and inspection has 'implied a distrust of professionals doing their jobs properly' (Anning and Ball 2008, p. 7).

The concept of 'quality' in the early years has been much discussed and problematised over past decades (Dahlberg et al. 2007; Moss 1994; 2005; Moss and Pence 1994; Munton et al. 1995; Penn 2000; Woodhead 1998). Pence and Moss (1994) recognise it as a relative, values-based and therefore subjective notion and the same can be said of 'success'. Considering the range of stakeholders involved in early years services, this makes the process of definition extremely complex. Approaches have often involved the examination of structures (resources used in the provision of care, for example physical environment, materials and people in the setting) and processes (the activities that constitute care, for example interactions involving both people and materials) in relation to outcomes. Particularly those relating the latter to children's educational attainment or measurable aspects of 
development (Moss 1994; Munton et al. 1995; Sylva et al. 2004). There are, however, other approaches. For example, Lilian Katz (1993) argues that definitions of 'quality' in early years services must be based on multiple perspectives derived from all of those involved. As part of this, the 'inside perspective' of practitioners is considered essential and Katz argues the importance of their sense of 'professionalism' which she attributes in part to experience and personal values (1993, p. 7). Early years practitioners have been among the stakeholders consulted in recent UK Government-commissioned research and evaluations of the 'effectiveness' of early years services (Deakin and Kelly 2006; DfES 2007; DfES 2008; SirajBlatchford and Siraj-Blatchford 2010a; b; Sylva et al. 2004). Some of these findings are considered below, specifically in relation to the children's centre context. However, there is limited evidence of practitioners' views on what constitutes 'quality' and 'success' in their work with young children and their families and of the contextual factors that may influence their views. The Understanding Quality project was intended to address a need for research that can provide further empirical evidence to complement recent large-scale surveys and provide further insight into the ways that practitioners operate within the current context.

\section{Children's Centres}

Sure Start Children's Centres are defined as 'service hubs where children under five years old and their families can receive seamless integrated services and information' (DCSF 2010). It is important to note that this idea is not new and these are based in part upon models that date back to the 1960s or perhaps further. A report by the Eurydice Network (2009) cites evidence from the USA and Europe that a centrebased approach with strong parent involvement, parent education and family support is effective in social-emotional and socioeconomic outcomes such as self-esteem, 
work attitude, sociability, decreased delinquency, less need for medical care and welfare support, higher employment rates and higher incomes. The Eurydice Network report describes Sure Start as interesting in terms of the major role of parents in local programmes and its potential impact upon future policy to tackle inequality. However, a report by the European Commission (2009) criticises Sure Start for being overambitious as well as vulnerable to political trends, particularly in terms of short term funding, making the point that early childhood intervention alone cannot redress the effects of poverty and disadvantage.

The pattern of provision in a Sure Start Children's Centre can be highly complex as centres integrate government-funded nursery provision with privatelyfunded childcare as well as health, social and educational services for adults as well as children. This means that there may be several funding streams within any one centre demanding high skills of financial management. Many of the Sure Start Children Centres have required the transformation of existing local provision, for example nursery schools and day care centres, into integrated centres. The transformation of physical spaces and ways of working has presented professionals and institutions with multiple challenges (Anning et al. 2010; Baldock et al. 2009; Roche and Tucker 2007) and Warmington et al (2004) suggest that current policy may be running ahead of the conceptualisations and learning required to effect new forms of practice. Some impact studies have found that the quality of Sure Start children's services is increasing in terms of a number of measurable effects for children and families, for example social development and social behaviour outcomes (DfES 2008). But others have found that centres are not meeting all the challenges demanded of them in terms of managing expanding staffing and implementing new staffing structures, negotiating funding arrangements with agencies, consulting local stakeholders and project 
managing new buildings and adopting new ways of working in multi-agency teams (DfES 2007). Interestingly, it seemed that the providers consulted considered the personal qualities of staff to be critical to achieving quality services. Practitioners stated that decisions were based on the Sure Start vision and their professional knowledge but were also informed by 'intuition' and 'empathy' (DfES 2007a, p. 95). These findings deserve further examination, as do the challenges that impact upon the daily lives and understandings of practitioners.

\section{The project}

The Understanding Quality project aimed to examine practitioners' perspectives across a range of early years settings and this article considers the data collected from eleven Sure Start Children's Centres, focusing on the views of the 115 practitioners working in these settings. The centres, located in two London boroughs and two shire counties, were recruited through the recommendations of local authorities, higher education colleagues and professionals working in the field based upon their own indicators of good practice. Whilst it is not claimed that the sample was in any way representative, the selection of a range of socio-economic contexts, which included inner city, outer city, suburban and rural localities and inhabited by ethnically diverse communities, was intended to ensure that the analysis took account of the specificities of local contexts. Contextual information on the centres in the study sample is provided in the table below. This is based on information provided by practitioners as well as data from Ofsted reports current at the time of data collection (May 2007 March 2008). National average statistics are taken from DCSF (2008) Pupil Characteristics and Class Sizes in Maintained Schools in England: January 2008, Statistical First Release 09/2008. 
A symbolic interactionist approach was selected (Schwandt 1998) in order to focus upon the nature of the interactions and the meanings that the actors construct from them, in this case the meanings that early years practitioners construct in relation to 'quality' and 'success' within the context of their setting.

A range of methods was used, following ESRC-approved ethical procedures around informed consent and confidentiality. Semi-structured individual interviews were designed to gather information about practitioners' professional histories and values (supplemented by a biographical questionnaire), their understandings of the contexts of the settings (structure, aims and purposes) and their perspectives on 'quality' and 'success', which included an exploration of their ideals, aspirations, inspirations and constraints. Focused discussions involved group activities and discussions about the concepts of 'quality' and 'success' in early years settings and also provided us with the opportunity to observe relationships and interactions and to draw inferences about the way the staff group worked together. Implicit understandings were investigated through environmental observations and documentary analysis of setting policies and procedures.

Although a significant number of practitioners in each setting gave their views, the field visits were limited to two days, making it impossible to draw firm conclusions about the ways that practitioners' definitions of 'quality' and 'success' were enacted. However, the methods fit the primary aim which was to investigate practitioners' understandings across a range of contexts, in order to 'highlight any tensions between the particular and the universal.... and to understand how they are qualified by local conditions, and thus to develop more sophisticated descriptions and...explanations' (Miles and Huberman 1994, p. 172). 


\section{Analysis}

Transcripts were coded and analysed to identify emerging themes then compared using a series of matrices as part of the constant comparison method (Miles and Huberman 1994). It is important to note that any common factors do not constitute a straightforward list that could be used to provide a model of a 'successful' children's centre. Issues were expressed and understood in diverse ways and given different weightings. Aspects of Engeström's activity theory have provided a useful lens for gaining insight into the processes that take place within complex workplaces such as these (Anning et al. 2010; Anning et al. 2008; Avis 2007; Carlisle et al. 2006; Daniels et al. 2007; Leadbetter et al. 2007; Engeström 2001; Ratner 1999; Engeström et al. 1995). The theory addresses the significance of socio-historical context in considering individual perspectives, with the emphasis on personal and local history. Practitioners can be characterised by their particular professional background and training but individual work histories and personal lives give each a set of unique values and beliefs. Engeström's 'boundary crossing' is a significant concept as 'joined up' working policies require practitioners to interact collaboratively in new and often unfamiliar ways, transcending professional borders (Engeström 2001; Engeström et al. 1995). In addition, Glisson and Hemmelgarn (1998, p. 415) suggest that effective multi-agency working relies on 'positive organisational climates' based around relationships and shared attitudes. These concepts have provided ways to interpret practitioners' definitions of 'quality' and 'success' and the factors that they perceive to enable or inhibit them in the achievement of these in their current setting, as we shall see in the discussion of findings. 


\section{Findings}

\section{Practitioners' perceptions of 'quality'}

Practitioners' perceptions were influenced by the particular context of their centre and their individual histories as well as the wider political agenda (Alexander 2009; 2010; Cottle and Alexander 2011). Individual histories influenced practitioners' views on 'quality' in a number of ways. Some of the aspects discussed included their particular educational background and their professional heritage, so initial and continuing training related to their specific role was valued highly. Many felt that they had learned or were learning 'what works' from experience; this might be whilst working within one setting or perhaps working in several different contexts had shaped their views. Others mentioned mentors within the work place and influential figures, for some these figures were linked to their family values, either when they were growing up or now that they were parents themselves. Several discussed the importance of developing their own philosophy and how important the culture of the setting was in this respect.

I sort of hunted around for jobs and it took me quite a long time to find somewhere that was actually functioning in a way that I felt that I could learn a lot from and also fitted in with my philosophy. (Churchill Children's Centre, Teacher)

Conceptions of quality services within a centre frequently revolved around the experiences practitioners wanted for both children and families, being flexible and responsive to individual needs.

It's not only about meeting the children's individual needs but recognising what the family's needs are and being able to support them however we can. It may be sometimes we have to bring in external agencies to support them. It may be that sometimes a parent needs an opportunity to have a conversation with you and ask for your advice or for you to ask their advice... So I think a combination of all of those things to me means that you're providing 'quality' within a setting. (Stockton Children's Centre, Head of Centre)

Respectful relationships were seen as crucial to providing a quality service in all centres: 
'Quality' for me is a well organized environment, with adults working in the team who have a shared ethos and who hold the child at the centre of everything they do. Families who feel welcomed and comfortable and...it's mutual respect, I think, between adults and children and staff and parents...I mean everyone who uses our centre, I think that's the key. (Chandlers Children's Centre, Head of Teaching)

The Sure Start vision (Chandler 2006) (DfES 2003b) seemed compatible with practitioners' personal and professional values and ideals in the most part, as indicated above, confirming the findings of the NESS impact studies (DfES 2007b). But achieving or working towards these visions frequently involved struggle and 'struggle' was a pervasive strand in the data. Practitioners in each of the research settings talked about this in one form or another, in terms of the struggle to become established in the community, to form relationships with parents, to fulfil expectations. These struggles are discussed further below in relation to practitioners' endeavours to meet national policy requirements, as well as their efforts to achieve role clarity and shared understanding within the particular context of their individual settings. There was also evidence of the weight of expectation upon staff working in Sure Start Children's Centres. Practitioners spoke of the emotional complexity of their role and the need to achieve 'a balance of sensitivity, empathy and professional boundaries' in their relationships with children and families (Stockton Children's Centre, Head of Centre), but this is no easy task.

It's the kind of job where there's no right or wrong answer because it's all about you. At the end of the day it's how you affect the lives of everybody because you're dealing with people that are sometimes sad, emotional, depressed, have a lot of problems. And ...it's not sitting at a computer...you can't just erase it and it's not going to make it better...it's ongoing, that's what I'm trying to say. It's kind of different every day. (Rosewood Children's Centre, Early Years Educator)

There is a body of literature that has established emotions as essential to quality provision for young children (Dahlberg and Moss 2005; Edwards et al. 1998; Freire 1999; Nias 1999; Osgood 2006; Taggart 2011; Vogt 2002; Webb and Vulliamy 2002). This can result in heavy demands on practitioners and several heads discussed 
concerns for the emotional health of their staff. As a further challenge, Osgood (2006, p. 8) argues that practitioners are self-regulated by internal constructions of their professionalism, describing this as an 'ethic of care', but that this runs counter to the dominant discourses that revolve around externally prescribed standards against which practitioners must measure their competence. Certainly, the Ofsted inspectorate's judgements of effectiveness and children's attainments according to the statutory guidance were discussed in all of the settings but these dominated practitioners' definitions in only two of the eleven children's centres. Others felt strongly that 'quality' should not be defined as a product:

I think that whole outcomes driven thing is hugely damaging and I find myself as playing two games. I play one which is for Ofsted and I play another which suits my philosophical viewpoint. So I have developed mechanisms whereby my own staff can actually respond to that whole outcomes debate. We do it in...a way that does not pervade what we do week on week..... We take the data from those snapshots...three times a year, to actually inform us in terms of being able to have the conversation with the school improvement partner, with Ofsted, but actually we refuse to be driven by that...because life is much more than that. Children are too valuable for that. (Northfield Children's Centre, Head of Centre)

Hoyle and Wallace (2007) would term the attitude above 'principled infidelity' and similarly resistant attitudes were evident to varying degrees in other centres. For example one practitioner saw the importance of working towards positive Ofsted judgements as a 'necessary evil' in order to achieve locally-determined aims. This was also the case at another children's centre where the Head felt they could now work towards their preferred goal of becoming a stronger 'voice' within the local authority as a result of their recent Ofsted-defined 'success'. Tanner, Welsh and Lewis (2006) argue that the standards-based approach adopted by the Labour Government should be considered less an aspiration and more a useful starting point from which stakeholders can develop their own contextualised definitions of 'quality'. This appears to represent the views expressed in most of the children's centres in our sample. The elusive yet dynamic nature of 'quality' emerged as a major theme in the 
data, that it is impossible to achieve because there is always something that could be improved.

Conceptions of 'quality' were largely elicited through asking participants to imagine what their ideal setting would be like. These became more specific when participants discussed the realities of putting their values into practice within their setting. Glisson and Hemmelgarn (1998) group attitudes, understandings and relationships under the collective label 'organisational climate', stating that settings are more likely to be successful in their aims if staff have 'higher levels of job satisfaction, fairness, role clarity, cooperation, and personalisation, and lower levels of role overload, conflict, and emotional exhaustion' (1998, p. 461). The practitioners in the Understanding Quality project perceived a number of dimensions similar to these to have an impact upon their capacity to provide their definitions of quality services, notably practices intended to promote role clarity and shared understandings within the setting. But these had to be balanced against a considerable amount of externally imposed demands, often viewed as constraints.

\section{Externally imposed constraints}

A lack of time was one of the most commonly perceived constraints with practitioners in ten out of the eleven centres commenting on the bureaucracy and increased paperwork generated by government initiatives.

I think we all get a sense of confusion about wanting to be with the children and be in there at grass roots and getting frustrated about paperwork and that taking away from our energy levels.

(Northfield Children's Centre, Teacher)

This response typifies the feelings of many practitioners. Northfield was going through the transition from nursery school to Sure Start Children's Centre, as was the case with three other centres in our sample, whilst a further four had recently completed this transformation. Practitioners in all of these centres were adapting to 
new roles and redefining their professional identity was proving daunting to most of those interviewed (Leadbetter et al. 2007). This situation was frequently accompanied by training implications and there was a palpable sense of pressure in some settings, including Northfield:

We are trying to absorb a lot of information at the moment because of the changes with the Children's Centre..... guess lots of us here are used to working with perhaps 3-5 year olds, so we now we are really trying to say, "Ok we've got younger children, what are their needs?" ...the curriculum is now changing as well...so there seem to be lots of changes going on and I think we are doing our best to absorb all of those changes.

(Northfield Children's Centre, Teacher)

There was a sense that these practitioners considered the changes to be overwhelming and beyond their control, perhaps even spiralling out of control.

It's like this fantastic cake, which we are, with every layer of every goody that you want.... and I look how wonderful it is and I show you this cake and you would be so impressed and you start to eat it but you can't swallow it because it's going to make you sick because there's too much.

(Northfield Children's Centre, Nursery Nurse)

The Headteacher at Northfield articulated a clear vision during interview. She stated that she was trying to build in time for practitioners to meet to develop a sense of ownership but this was difficult to do in the face of the rapid expansion of their services to the community, resulting in a perhaps more autocratic style of leadership than she would usually have favoured. Emanuel Children's Centre had been designated for two years but the Head of Centre expressed similar feelings, describing the sense of pressure that she felt in maintaining an overall sense of direction whilst being ready to respond to expansion and frequent changes to setting priorities imposed by external sources (Anning et al. 2010).

You've got more potential for things to go wrong as it gets bigger... as we come away from the nursery school...there are just not enough hours in the day and I think there is more and more administrative bureaucracy....Y ou just get your head around one system and the local authority says, "Actually, that's all gone out the window now. We're going to change it to this." And you have to have so much training...to get the new system in place. So the speed of change is really difficult.

(Emanuel Children's Centre, Head of Centre) 
Practitioners in eight of the eleven centres expressed a desire for more time to reflect or consolidate on increasingly complex roles and responsibilities. Physical space was a factor for nine centres with most of those seeing this as a constraint. Many of these were expanding or renegotiating their building space but building projects brought new challenges, for example several heads expressed apprehension at having to assume the role of project manager with little experience in this area. Funding was another source of anxiety and practitioners in five centres raised concerns about managing funds and sustainability.

\section{Role clarity}

Six of the eleven centres were introducing new staffing structures either to cope with expansion, to promote equality and shared vision or to meet policy demands. For example, Chandlers Children's Centre had implemented a form of 'single status' not long before the research visit, as the county council was attempting the 'harmonisation' of different terms and conditions in line with the national agreement discussed earlier (NJC 1997, p. 4.9.30). But this was proving problematic as discussed by the practitioner below:

Everyone is an 'early years educator'...if they do lunches they are an 'early years educator'...if they do special needs they are an 'early years educator'. I think it's just making everyone coming together more than be separate, but at the end of the day I have got a nursery nurse qualification, and if anyone asks I say that.

(Chandlers Children's Centre, Early Years Educator)

Restructuring the workforce involves breaking down any hierarchical barriers and developing of a sense of shared identity, purpose and ownership (Anning et al. 2010; Baldock et al. 2005; Leadbetter et al. 2007). Although this was the vision espoused by the senior management team at Chandlers, this example demonstrates that it is difficult to achieve when decisions that impact upon professional identity are imposed upon staff. Although the practitioner above understood the expressed purpose of this 
strategy, she did not feel any sense of ownership and the redefinition of her professional identity was proving demoralising (Leadbetter et al. 2007). There were also financial implications which were engendering tensions amongst staff as longeremployed practitioners served out old contracts whilst others were employed under new conditions that sometimes meant a reduction in pay (Vevers 2006). This interpretation of 'single status' masks a more serious issue relating to the low pay and poor conditions of the early years workforce in the UK. Until these structural factors are tackled at policy level, issues of status will continue to impact upon the quality of services resulting in high levels of staff turnover and continuing problems with recruitment (Osgood 2009; Owen and Haynes 2010).

Role clarity is a term often taken to mean a rigid job description and the blurring of boundaries described above would then seem to contradict that clarity. But Anning et al. (2010) found that blurring roles can actually be a dynamic and effective process if every worker has a clear sense of the ways in which they contribute to the purposes of the team. There was no 'single status' at Emanuel Children's Centre but all of the practitioners interviewed expressed a clear sense of both individual and collective purpose. There was also a positive ethos in that they expressed confidence that their opinions were valued and acted upon by their colleagues and leaders. The Head discussed job shadowing as a strategy they employed to promote the understanding of different roles within the Centre.

We did a lot of job swaps and...we're doing work shadowing so that a teacher will know what a family support worker does and the family support worker will know how to work in a classroom. (Emanuel Children's Centre, Head of Centre)

This draws on Engeström's concept of 'boundary-crossing' (Daniels et al. 2007, p. 532) and appeared to have been successful in creating a sense of shared ownership in this centre though clearly there are logistical challenges involved in this strategy. 


\section{Shared understanding}

Practitioners in nine centres identified shared understanding as integral to 'quality'.

Some saw this as the goal of an ever-evolving process and most felt that were working towards it rather than having achieved it. For example, Brackenridge became a Sure Start Children's Centre shortly before the fieldwork visit. Physically, the Centre consisted of two separate buildings on the same site. One building housed both the nursery school and a child development centre. The child development centre was longer established and operated on a referral-only basis, consisting of 'a multi-agency team that provides assessment and ongoing care planning for children with special needs' (Brackenridge Children's Centre website). The other building housed extended services including before and after school clubs and lunch for children who attended the nursery as well as other children in the community for a fee (although social service referral children who attended the Sure Start Children's Centre had lunch in the nursery in the main building). This building was called the Greenlands Early Years Centre; it had been open for a year prior to designation and had a separate manager to coordinate the complex services on offer. The newly appointed Sure Start Children's Centre Manager gave evidence of the impact of the specific historical context, including the complex system of funding, on the organisational climate and coherence of services:

\footnotetext{
The sign out here says... Brackenridge Children's Centre. Then there's another sign that identifies the nursery school and the child development centre. Then there is another sign down at the [extended services] Centre that says 'Early Years' because it was another piece of joint partnership...between the county council, Brackenridge Nursery School and the Greenlands Centre, which is the Church group. The church group have put more money in so they decided to call it the Greenlands Early Years Centre. .....I think that is confusing for families, which is something we probably need to think about, but this is the difficulty when you've got different people with their views.

(Brackenridge Children's Centre, Children's Centre Manager)
}

The disparate understandings of purpose here had an enormous impact on staff, parents and particularly the children, some of whom had to negotiate several 
transitions a day within the Centre itself. Confusion was also evident in the wider community:

I've got to consult with all these other providers, I think again they can't see the point of it, they don't understand what the Children's Centre has got to offer them......... we've had an awful lot of interest from health workers and groups to actually run things in the Centre but of course I am restricted to what space I've got and how that's going to impact on the other staff, and... So yes challenging would probably be the best way to put it...

(Brackenridge Children's Centre, Children's Centre Manager)

There is no doubt that this Sure Start Centre had a complex physical set up, but interestingly the practitioners did not perceive this in itself to be a constraint in itself, rather it was accommodating different perspectives and negotiating a shared identity that was the greater challenge. It was difficult to organise meetings between the different sections of the Centre due to the part-time status of many members of staff, but anecdotes and observations also illuminated tensions between the different teams and an apparent reluctance to collaborate on the creation of a shared vision. This situation suggests that, although it is possible for co-location to 'make services more accessible to users, improve inter-professional relationships and ways of working' (DfES 2003a, p. 69), it is no guarantee. Daniels et al. (2007, p. 532) attribute tensions such as these to 'destabilised traditional professional roles, identities and values'. They advocate a dialogic exploration of the different professional philosophies in order to promote 'boundary crossing' and new integrated ways of working. MacNaughton (2005) argues that in order to effect change in the interests of children, practitioners need to move away from individual actions and attitudes to become critically knowing early childhood communities. These communities would be based on diversity and localised understandings with a goal of achieving 'positive dissensus' as opposed to consensus (MacNaughton 2005, pp. 201-3). Positive dissensus follows a cycle akin to Engeström's (2001, p. 137) notion of 'expansive learning' 
where teams come together with different knowledge, expertise and histories to pursue a common goal working through 'processes of articulating differences, exploring alternatives, modelling solutions, examining an agreed model and implementing activities' (Anning et al. 2010, p. 12). Practitioners in four centres placed high value on developing shared understandings in this way. For example, Stockton was a relatively new children's centre with a team of practitioners who valued open dialogue as was demonstrated through observations as well as interviews.

We've got a lot of things changing with the Children's Centre and I think we need to understand that a bit more, but it is embryonic right now........ If I can understand why we are doing it, I can agree or disagree and that's fine, and I am quite happy to tell you if I agree or disagree.... If you know where you are coming from you can work with it, if you have got no idea where it is coming from then I don't think you can respect it, embrace it, or work with it.

(Stockton Children's Centre, Nursery Nurse)

A number of practitioners within two of these four centres suggested that effective or 'inspiring' leadership was one of the main contributory factors in facilitating an organisational climate that was conducive to this kind of collaboration. But leadership was barely mentioned in the other two centres, aside from brief descriptive references to new management structures or the new Head with some intimation that changes had yet to embed. These findings suggest that leadership is a factor that deserves further consideration in exploring the ways that shared understandings can be achieved as part of further in-depth research into the various factors that make up the organisational climate and culture of a children's centre.

\section{Conclusions}

Recent policy innovation has played a vital role in instigating a process of transformation of children's services in the UK. However the competing economic and social aims of the former Labour government have engendered tensions that can be daunting to early years' practitioners. On the one hand, 'joined up' working 
policies require flexibility and contextualised responses to community needs whilst other policies advocate a single standards-based position on 'quality' whereby settings are governed through a system of centralised targets. As Moss (2004) argues, the latter can limit the potential for Sure Start to undertake significant experiments at the local level. The practitioners working in the children's centres in this sample aspired towards responsive, localised services as part of their visions of 'quality'. But these visions and the challenges they faced in achieving them were influenced by practitioners' personal histories and the particular context of their setting as well as the wider political agenda (Alexander 2009; 2010; Cottle and Alexander 2011). The data here suggest that the concept of 'quality' can be elusive and dynamic and that positive relationships, open dialogue and critical reflection are key to developing the shared understandings which enable responsive services for children and families. Tensions can play a part in enabling a dialectical process of critical thinking, motivating practitioners to challenge rules and to construct creative and flexible responses to the needs of their community (Daniels et al, 2007). But whether challenges are perceived as overwhelming or merely as 'hurdles' appears to be dependent upon the particular organisational climate of each setting, in other words the attitudes and understandings of the practitioners and their relationships (Glisson and Hemmelgarn 1998, p. 416). Just as there is no one-size fits all model of a children's centre (Anning et al. 2010), there is no single way to develop a shared vision and a sense of ownership. Most of the centres involved in this project were experimenting with strategies to promote shared understanding and role clarity, for example through flattened hierarchies and job shadowing, with varying degrees of success in the eyes of the practitioners involved. They acknowledged that 'quality' had to be defined at least in part according to measurable, standardised outcomes, 
particularly in the current political climate. But many resisted product-based conceptions in favour of process-orientated views of 'quality', whilst simultaneously recognising the integral role of structural factors, for example resources, physical space and funding, in providing the conditions for these processes. Siraj-Blatchford and Siraj-Blatchford (2010b) draw attention to issues that need to be resolved at policy level in this respect, for example agreed and improved working and pay structures and further training to develop clear, shared understandings of what 'quality' means in the context of integrated working in early years services. This is particularly relevant in the light of the new Coalition Government plans to take Sure Start Children's Centres back to a system of targeted intervention (HM Government 2010) moving away from the comparatively social democratic orientation that had evolved from Labour Government policies; the vision of centres as basic provision for all children. Social class divisions have been widening since the introduction of neoliberalism (Toynbee and Walker 2008). Not only does the new Government policy seem likely to maintain this situation, but it continues to charge early years practitioners in Sure Start Children's Centres with the responsibility of alleviating the effects of poverty. This whilst, in all likelihood, retaining low levels of pay and status within the sector, especially given the current economic climate. 


\section{Bibliography}

Alexander, E. 2009. Understanding quality and success in early years settings / practitioners' perspectives. Swindon: ESRC.

Alexander, E. 2010. A successful child: Early years practitioners' understandings of quality. Early Years 30, no. 2: 107-18.

Anning, A. and M. Ball. 2008. Improving services for young children : From sure start to children's centres. London: SAGE.

Anning, A., D. Cottrell, N. Frost, J. Green and M. Robinson. 2010. Developing multiprofessional teamwork for integrated children's services: Research, policy and practice. Maidenhead: Open University Press.

Anning, A., J. Cullen and M. Fleer. 2008. Early childhood education : Society and culture. London: SAGE.

Avis, J. 2007. Engeström's version of activity theory: A conservative praxis? Journal of Education and Work 20, no. 3: 161-77.

Baldock, P., D. Fitzgerald and J. Kay. 2005. Understanding early years policy. London: Paul Chapman.

Baldock, P., D. Fitzgerald and J. Kay. 2009. Understanding early years policy. second ed. London: Paul Chapman.

Carlisle, K., T. Gallagher, R. Kilpatrick and H. Daniels. 2006. Competition or collaboration? A critique of multi agency working in northern ireland to meet the needs of young people at risk of exclusion from mainstream schooling. Paper presentat at the British Association for International and Comparative Education Conference, 8-10 September 2006, in Queen's University Belfast.

Cottle, M. and E. Alexander. 2011. Quality in early years settings: Government, research and practitioners' perspectives. British Educational Research Journal iFirst Article: 1-20.

Dahlberg, G. and P. Moss. 2005. Ethics and politics in early childhood education. London: Routledge.

Dahlberg, G., P. Moss and A.R. Pence. 2007. Beyond quality in early childhood education and care: Languages of evaluation. 2nd ed. London: Routledge.

Daniels, H., J. Leadbetter, P. Warmington, A. Edwards, D. Martin, A. Popova, A. Apostolov, D. Middleton and S. Brown. 2007. Learning in and for multiagency working. Oxford Review of Education 33, no. 4: 521-38.

Daycare Trust. 2010. Press releases. London: Daycare Trust.

Dcsf. 2006. The early years foundation stage (eyfs): Consultation on a single quality framework for services to children from birth to five, ed. Department for Children Schools and Families: DCSF.

Dcsf. 2007a. The early years foundation stage : Setting the standards for learning, development and care for children from birth to five Every child matters, change for children. Rev. ed. Nottingham: DCSF Publications.

Dcsf. 2007b. Early years foundation stage: Setting the standards for learning, development and care for children from birth to five. In Every Child Matters, change for children, ed. Department for Children Schools and Families, 1 pack. Nottingham: London, DCSF.

Dcsf. 2010. Sure start children's centres. http://www.surestart.gov.uk/ accessed 19 January 2010: United Kingdom Department for Children, Schools and Families. 
Deakin, G. and G. Kelly. 2006. Children's workforce research. London: Department for Education and Skills.

Dfee. 1998. Meeting the childcare challenge, ed. Department for Education and Employment, 128 p. London: London, HMSO.

Dfes. 2003a. Every child matters. London: United Kingdom Department for Education and Skills (TSO).

Dfes. 2003b. Sure start guidance 2004 - 2006: Overview and local delivery arrangements, ed. Department for Education and Skills: DfES Publications.

Dfes. 2006. Children's workforce strategy: Building a world-class workforce for children, young people and families, ed. Department for Education and Skills, 102 p. London: London, DfES.

Dfes. 2007a. National evaluation report: Understanding variations in effectiveness amongst sure start local programmes, ed. Skills, Dfea. Nottingham: London, DfES.

Dfes. 2007b. National standards for leaders of surestart children's centres. In Every child matters, change for children, 18pp. Nottingham: DfES Publications.

Dfes. 2008. The impact of sure start local programmes on three year olds and their families. Nottingham: United Kingdom Department for Education and Skills.

Edwards, C., L. Gandini and G. Forman. 1998. The hundred languages of children : The reggio emilia approach [to early childhood education] - advanced reflections. Norwood: Ablex.

Engeström, Y. 2001. Expansive learning at work: Toward an activity theoretical reconceptualization. Journal of Education and Work, 14, no. 1: 133-56.

Engeström, Y., Engeström, R. \& Kärkkäinen, M. (1995) Polycontextuality and boundary crossing in expert cognition: Learning and problem solving in complex work activities Learning and Instruction, 5(4), pp. 319-336.

European Commission/Nesse. 2009. Early childhood education and care - key lessons from research for policy makers. In Report submitted to the European Commission by the NESSE network of experts.

Eurydice Report. 2009. Early childhood education and care in europe: Tacking social and cultural inequalities. Brussels: Education, Audiovisual and Culture Executive Agency.

Freire, P. 1999. Pedagogy of the heart. New York: Continuum.

Glisson, C. and A. Hemmelgarn. 1998. The effects of organizational climate and interorganizational coordination on the quality and outcomes of children's service systems. Child Abuse \& Neglect 22, no. 5: 401-21.

Hm Government. 2010. The coalition: Our programme for government. London: Cabinet Office.

Hm Treasury. 2004. Choice for parents, the best start for children: A ten year strategy for childcare, 83 p. London: HMSO.

Hoyle, E. and M. Wallace. 2007. Educational reform: An ironic perspective. Educational Management Administration \& Leadership 35, no. 1: 9-25.

Katz, L.G. 1993. Multiple perspectives on the quality of early childhood programmes. European Early Childhood Education Research Journal 1, no. 2: 5-9.

Leadbetter, J., H. Daniels, A. Edwards, D. Martin, D. Middleton, A. Popova, P. Warmington, A. Apostolov and S. Brown. 2007. Professional learning within multi-agency children's services: Researching into practice. Educational Research 49, no. 1: 83-98. 
Macnaughton, G. 2005. Doing foucault in early childhood studies: Applying poststructural ideas Contesting early childhood series, . London ; New York: Routledge.

Miles, M.B. and A.M. Huberman. 1994. Qualitative data analysis : An expanded sourcebook. 2nd ed. London: Sage.

Moss, P. 1994. Defining quality: Values, stakeholders and processes. In Valuing quality in early childhood services : New approaches to defining quality, eds Moss, P and Pence, A, 1-9. London: Paul Chapman.

Moss, P. 2004. Sure start. Journal of Education Policy 19, no. 5: 631 - 34 .

Moss, P. 2005. Making the narrative of quality stutter. Early Education \& Development 16, no. 4: 405-20.

Moss, P. and A. Pence eds. 1994. Valuing quality in early childhood services : New approaches to defining quality. London: Paul Chapman.

Munton, A.G., A. Mooney and L. Rowland. 1995. Deconstructing quality: A conceptual framework for the new paradigm in day care provision for the under eights. Early Child Development and Care 114: 11-23.

Nias, J. 1999. Primary teaching as a culture of care. In School culture, ed. Prosser, J. London: Paul Chapman.

Njc. 1997. National agreement on pay and conditions of service, ed. National Joint Council for Local Government Services $(\mathrm{Njc})$.

Osgood, J. 2006. Deconstructing professionalism in early childhood education: Resisting the regulatory gaze. Contemporary Issues in Early Childhood 7, no. 1: 5-14.

Osgood, J. 2009. Childcare workforce reform in england and 'the early years professional': A critical discourse analysis. Journal of Education Policy 24, no. 6: $733-51$.

Owen, S. and G. Haynes. 2010. Training and workforce issues in the early years. In Contemporary issues in the early years, eds Pugh, G and Duffy, B, 195-208. London: SAGE.

Pence, A. and P. Moss. 1994. Towards an inclusionary approach in defining quality. In Valuing quality in early childhood services : New approaches to defining quality, eds Moss, $\mathrm{P}$ and Pence, A. London: Paul Chapman.

Penn, H. 2000. Early childhood services : Theory, policy and practice. Buckingham [England] ; Philadelphia, PA: Open University Press.

Penn, H. 2008. Understanding early childhood: Issues and controversies. 2nd ed. Maidenhead: Open University Press.

Pugh, G. 2010. The policy agenda for early childhood services. In Contemporary issues in the early years, eds Pugh, G and Duffy, B, 7-20. London: SAGE.

Ratner, C. 1999. Three approaches to cultural psychology: A critique. Cultural Dynamics 11, no. 7-31.

Roche, J. and S.A. Tucker. 2007. Every child matters: 'tinkering' or 'reforming' - an analysis of the development of the children act (2004) from an educational perspective. Education 3-13: International Journal of Primary, Elementary and Early Years Education 35, no. 3: 213-23.

Schwandt, T. 1998. Constructivist, interpretivist approaches to human enquiry. In The landscape of qualitative research: Theories and issues, eds Denzin, Nk and Lincoln, Ys. Thousand Oaks, CA: Sage.

Siraj-Blatchford, I. and J. Siraj-Blatchford. 2010a. Improving children's attainment through a better quality of family-based support for early learning, 70 . 
London: Centre for Excellence and Outcomes in Children and Young People's Services (C4EO).

Siraj-Blatchford, I. and J. Siraj-Blatchford. 2010b. Improving development outcomes for children through effective practice in integrating early years services, 60 .

London: Centre for Excellence and Outcomes in Children and Young People's Services (C4EO).

Sylva, K., E. Melhuish, P. Sammons, I. Siraj-Blatchford and B. Taggart. 2004. The effective provision of pre-school education (eppe) project: Findings from preschool to end of key stage 1. London Sure Start.

Taggart, G. 2011. Don't we care?: The ethics and emotional labour of early years professionalism. Early Years 31, no. 1: 85-95.

Tanner, E., E. Welsh and J. Lewis. 2006. The quality-defining process in early years services: A case study Children \& Society 20, no. 1: 4-16.

Toynbee, P. and D. Walker. 2008. Unjust rewards: Exposing greed and inequality in britain today. London: Granta Books.

Vevers, S. 2006. At a loss. Nursery World, http://www.nurseryworld.co.uk/news/719631/loss/ (accessed June 17 2011).

Vogt, F. 2002. A caring teacher: Explorations into primary school teachers' professional identity and ethic of care. Gender and Education 14, no. 3: $251-$ 64.

Warmington, P.C., H.R.J. Daniels, A. Edwards, J. Leadbetter, D.M. Martin, S. Brown and D. Middleton. 2004. Interagency collaboration: A review of the literature: Report of stage 1 of the tlrpiii learning in and for interagency working project. Bath: ESRC.

Webb, R. and G. Vulliamy. 2002. The social work dimension of the primary teacher's role. Research Papers in Education 17, no. 2: 165-84.

Woodhead, M. 1998. "Quality" In early childhood programmes--a contextually appropriate approach. International Journal of Early Years Education 6, no. 1.

\footnotetext{
i This article draws on data from an ESRC-funded project entitled Understanding quality and success in early years settings: practitioners' perspectives (RES-061-23-0012). The project was undertaken by Dr. Elise Alexander and Michelle Cottle at the University of Roehampton and ran from January 2007 until May 2009. The data were collected between May 2007 and March 2008.
} 